\title{
Assessment and Simulation of the Responsive Demand Potential in End User Facilities: Application to an University Customer
}

\author{
C. Alvarez, Member, IEEE, A. Gabaldón, Member, IEEE, and A. Molina Student Member, IEEE
}

\begin{abstract}
Many problems have arose along with the practical implementation of restructured electrical business in USA and European Union such as lack of generation, network constraints, etc. A good example for these problems is the scarce participation of the demand in the electricity markets - energy, reserve and other ancillary services- problem that can be solved through new Demand Responsive Programs, aimed to replace the traditional Demand Side Management programs into voluntary demand participation programs.

A methodology for the generation of demand side bids and offers in large customer facilities and a real application to a university customer is presented in this paper. This methodology is based on knowledge of the physical processes involved in the electricity consumption and the flexibility in the required supply. The result of the methodology proposed is a set of Demand Packages, that can be used to participate in different electricity markets, whose possibilities -in the market arena- will be explored in a consequent paper.
\end{abstract}

Index Terms-Responsive Demand Participation, Electricity markets, Demand modeling

\section{INTRODUCTION}

$\mathbf{O}$ $\mathrm{NE}$ of the main shortcomings in the implementation of competitive electricity markets is the lack of participation of the demand in the involved activities, where the load has shown very reduced elasticity with respect to electricity prices and offers. Customer load participation in Electricity markets is likely to increase in the near future due, besides, to the need to increase the global efficiency of the electric energy supply process.

Electrical customer load may participate according to its flexibility in the consumption, what implies the classification of the involved processes according to the possibilities of consumption reduction/increase, capability of switching to other energy sources, facilities for energy storage ...

Large customers and electric energy commercializers may seek to participate by direct generation of demand offers and bids, that can enter the market place whereas small and residential customers could participate through specific programs promoted by aggregators.

In order to classify loads according to their supply requirements, it is basic to analyse all the different processes that conform the load. These individual processes need to be

C. Alvarez is with the Institute of Energy Engineering Universidad Politécnica de Valencia, 46010 Valencia (SPAIN); calvarez@die.upv.es

A. Gabaldón and A. Molina are with the Department of Electrical Eng. Universidad Politécnica de Cartagena, 30202 Cartagena (SPAIN); direccion@etsii.upct.es ranked according to the following criteria: priority (whether the supply can be curtailed or not), storage capability (whether the interruption of the process implies the suppression of the service provided by the appliance or not), rescheduling time (the time in advance that the specific process needs to be rescheduled), etc. All these characteristics may allow setting up the parameters for the required flexible supply system.

After this classification has been identified, the aggregation of similar individual processes has to be performed in order to quantify the quality and characteristics of the Demand Packages (DP) the customer may use to bargain in the marketplace. These packages can then be offered to generation or commercialising companies or can posted as demand bids in auction markets present in the power market arena.

This organisation of the load consumption has been somehow traditionally considered, where large customers have been able to identify the characteristics of their load and to apply for Interruptible and Time Of Use tariffs.

Different DP can be considered for the objectives stated before, according to the flexibility in which the control of the load elements can be performed. Each of this DP is characterised by the following parameters:

- Time horizon in which the number of demand elements and the absorbed power can be predicted. This time can rank in years or months, for long term load forecasting or shorter.

- Flexibility of these load elements, what informs about to what extent the foreseen demand can be modified and what is the rate in which these modifications can be performed. This flexibility depends both on the load structure and on the availability of communication and control systems.

According to these parameters, the following four packages are proposed here for the demand to participate in electricity markets:

- Long Term DP, where the amount of load demanded can be identified one year ahead. The processes included in this DP are those where some kind of long term decisions can be made (investment, customer activity reorganization, etc.). Actions oriented to Strategic Growth or Strategic Conservation can be considered here, actions that always involve some kind of investment. These long term strategies are not addressed in this paper

- Medium Term DP. The load that can be managed or scheduled with an horizon of 24 hours are included in 
this DP. This could include processes programmed in this span of time and could imply, according to the market conditions, for the customer to reschedule some tasks or activities, as well as the need to implement some control actions (taken by the customer and oriented to meet the predicted demand). These DP are well suited to participate in One Day ahead energy markets as well as in reserve markets, [1]. The participation in these markets would need extra communication requirements to provide the Market Operator with the exact amount of energy hourly traded by the customer.

- Short Term DP. The demand handled in this group of loads are those that can be foreseen and controlled in a one hour span of time, and could imply minor changes in the productive process or control of flexible specific loads. Loads that have some kind of storage facilities are candidates to form this group. These DP are very well suited to participate in balancing markets, where the balancing of the load is performed once every several minutes. The load reduction offers may be submitted up to some 30 minutes before the dispatch and the also may include the associated decremental cost. The participation in these markets would require extra communication requirements to provide the System Operator (ISO) with the exact amount of energy sub-hourly (such as every 5 minutes) traded by the customer allowing the ISO to validate the response of the customer.

- Dispatchable DP that include the loads that can be controlled in real time mode either in continuous or discrete pattern. These DP may allow the participation in ancillary services markets what requires control and two way communication for every load set participating in this DP. Typical, response time for these controlled load elements to participate as primary reserve (spinning reserve) is suggested in [2] within 20 cycles. Nevertheless, the participation of the load in this type of real time activity appears to be quite limited as far as the storage capability in customer facilities remains reduced in term of $\mathrm{kWh}$. This type of DP is not considered in this paper.

In order to organise the customer energy consumption in DP, a detailed physical description of the consumer processes has to be performed. Once identified these packages, the customer can offer them to market and system operators either directly or through a retailer. This last one could take advantage of the similar DP offered by homogeneous or heterogeneous customers so that more significant demand bids can be posted to energy markets ( 24 hours ahead), shorter term energy markets (up to 1 hour ahead), balancing markets (in horizon of tens of minutes) or ancillary services markets (where continuous dispatch is needed).

Not only load elements may be included in the DP but all the available Distributed Energy Resources (DER) in the customer facilities. One typical DER suitable to participate in load mix characterisation is the stand-by generators present in many customer facilities. These generators may be considered either alone or grouped to similar response loads.

The identification of the load flexibility is not an easy task for a standard customer as it depends very much on the nature of the processes involved in the energy consumption as well as in what the current technology may offer with respect to the customer processes control and monitoring.

This paper deals with the methodology for the identification of the energy consumption, the further aggregation into Demand Packages and, finally with the implementation issues for the application to an University Customer load.

The paper is organised as follows: Section II is devoted to the study of the characteristics of the general loads with respect to their flexibility. A first appliance classification, according to the load elements required later on, in terms of their availability for DP participation is also performed in this section. The most significant load components in a pilot experiment (the Universidad Politécnica de Valencia, in Valencia, Spain) are identified and classified in section III. Load modeling, implementation issues and simulation results are considered in section IV and, finally, some conclusions are shown in section $\mathrm{V}$.

\section{DEmand PARTicipation: LoAd Suitability}

The possibility of an electric load to participate in an offer implying energy reduction — demand offer-depends on the ability of the user to switch off or reduce partially the load demand while maintaining end use characteristics of such a load — comfort or processes - over certain levels.

Several factors are relevant to classify load capability for this purpose:

- Final service supplied by the electric load (thermal, illumination, mechanical, electronic ...)

- Storage capacity

- Rate of load switching

- Load dispatch facility

The first one refers to the energy conversion is being performed in the end user device, independently of the nature of the individual elements that may compose the load (for example, an Air Conditioning set is providing cold through the conversion of electrical energy into mechanical energy in a motor that powers a compressor). Electricity is more valuable than other energy sources due to its flexibility for energy conversion but, for a few end uses, other forms of primary energy can compete because their greater efficiency. Dual heating or cooling appliances are candidates to support dual energy systems (electricity and gas) and that has to be taken into account perform demand offers and bids.

The storage capacity is related to the ability of the whole process to store some kind of energy (electrical, thermal or in form of hydrogen) or some other "manufactured products" that can be used in any other time. The storage capability should provide the electric consumption process to be rescheduled over a specified time span. The energy storage capacity can be internal to the load (i.e. the load has a device or system to store the excess of electricity, with batteries or other, or the converted energy, as for example in form of ice for cool storage or heated bricks for heat storage). Sometimes the environment of the load has some kind of energy storage availability (or external storage) as, for example, the one provided by the storage capacity provided by the specific heat 


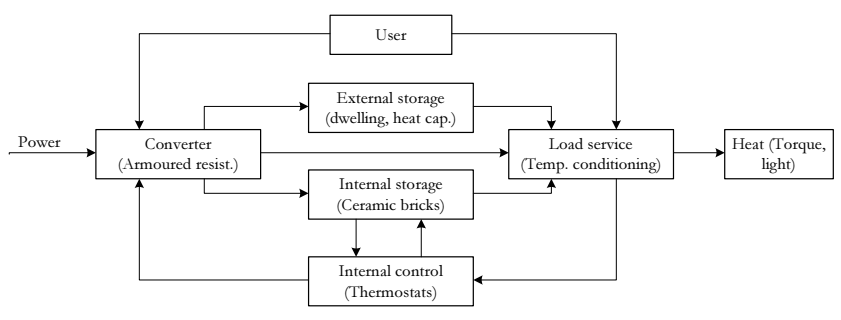

Fig. 1. Block diagram of an Energy Thermal Storage (ETS) electric load

of the air, walls, furniture, etc. located in an office or dwelling in an Air Conditioning/Heating load. The internal storage can be either partial or total related to the total energy provided by the electric load in a load cycle. Fig. 1 depicts a load where the two types of storage are present.

The third factor is related to the load demand behaviour. The load pattern of consumption, according to the electrical device nature, can be discrete or continuous. A continuous demand to accomplish the service provided by the load may result in a continuous electricity consumption (this is the case of lighting loads or computers) or in a discontinuous consumption (for example in a refrigerator or in most of Air Conditioning devices where the operating state is thermostat controlled). In both cases, the nature of the load demand is subjected to the random nature of the load usage what adds an additional discrete type uncertainty to the electrical behaviour of the load.

The switching pattern of an Air Conditioning load is shown in Fig. 2 where it can be observed that the electricity consumption depends both in the use of the load (the thermostat set point decided by the user) and the internal control mechanism. In this case, during the first test period the load is switching ON to OFF regularly. When the customer demands a higher service to the load $\left(4^{\circ} \mathrm{C}\right.$ reduction in the temperature demanded in this case) starting at time $t=250 \mathrm{~min}$, the switching rate increases until the customer demands the original temperature -at $t=450 \mathrm{~min}$ -

Thus, the rate of load switching condition the frequency and amplitude in which the demand of an individual load or an aggregation of them can be modified. It is interesting to note that in this type of loads, to switch the load supply ON or OFF could not result in electric energy increase or reduction as the load may be supplying the required service from stored resources. The availability of these loads to conform packages for energy reduction is limited in some time periods, as shown in Fig. 3.

Finally, the load dispatch capability refers to the availability of communication/control mechanisms, so that this load can be managed either in a local or remote fashion, and with the necessary response time to allow an effective control policy at an affordable economic cost.

The control performed upon the loads can be local, or exercised by control actions affecting only the load element (i.e., a local thermostat) or remote by some other control system. This control can be total (turn OFF the load with total loss of the service provided by the load when interrupted), or partial, where the electric load supply is bounded by cycling or voltage modulation policies (what results in a partial loss
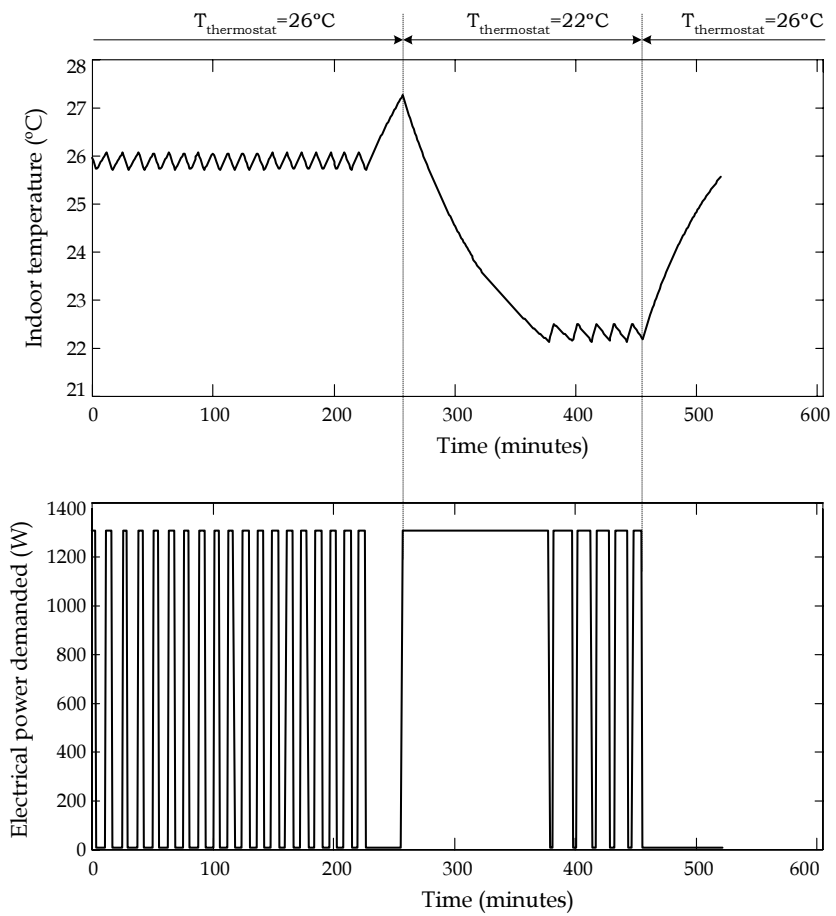

Fig. 2. Air Conditioning ON/OFF switching dynamic due to thermostat changes

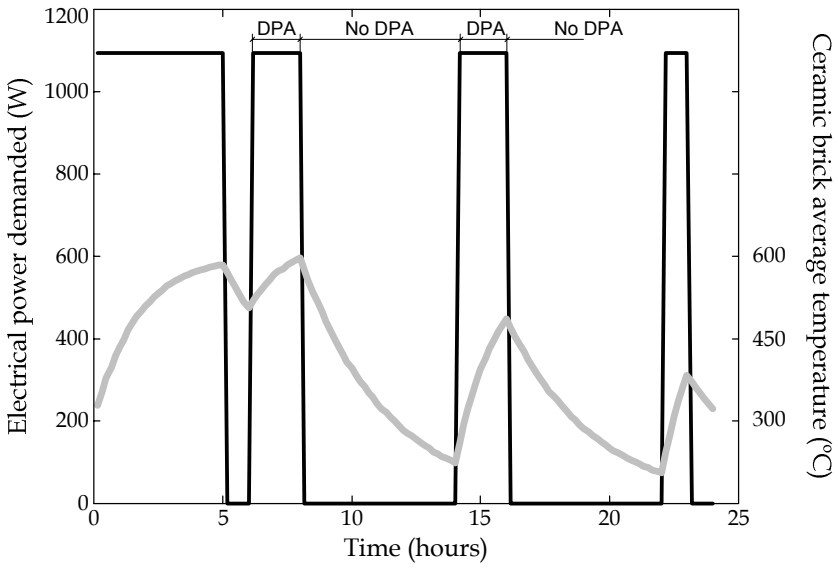

Fig. 3. ETS Heat Storage appliance switching rate and availability in energy offers (Note: DPA: Demand Participation Available, NoDPA: not available)

of the service provided by the load).

In order to find the suitability of the electrical loads to participate in demand reduction or modulation programs, the effect of the possible control actions in the power supply has to be evaluated and modelled. The most suitable way to account for all the different modelling requirements to be considered in the electrical demand bids generation is through Physically based load models, [3]-[5], that offers the possibility to model the joint behaviour of the electrical devices forming the load as well as all the associated physical devices.

From the previous considerations and the loads normally present in residential/commercial loads, a first classification according to their suitability for a flexible control is proposed in Fig. 4, where the suitability is classified in terms of Low, Medium and High. The duration of the control period is also 


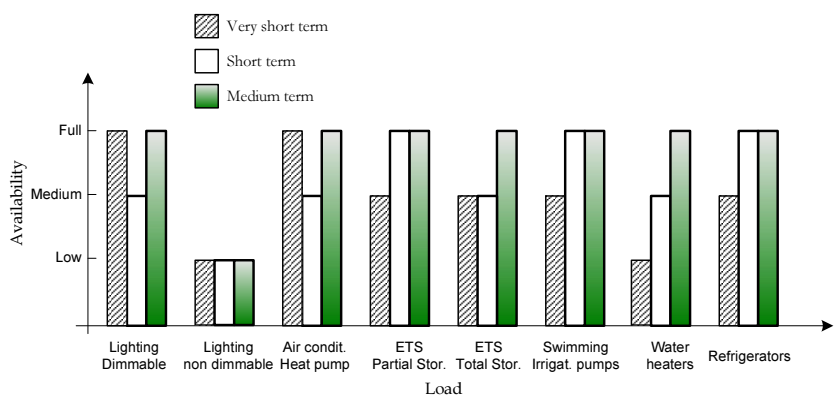

Fig. 4. Demand Response Availability for different loads

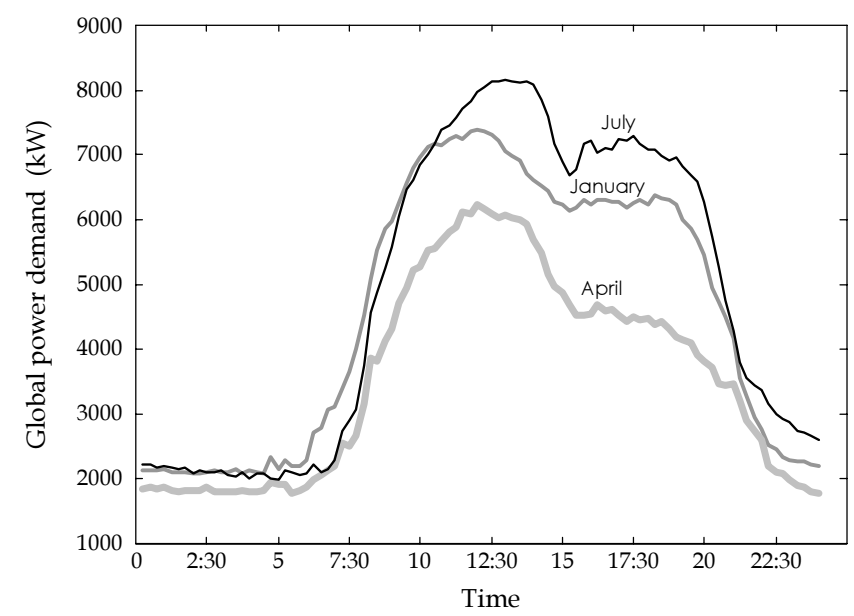

Fig. 5. Global load demand in the University (UPV) in three different months during the year 2002

indicated (hours or minutes).

\section{ApPlication to AN University CUSTOMER}

The load types conforming the Universidad Politécnica de Valencia (UPV) load mix are identified, described and classified in this section. The loads suitable to participate in Responsive Demand policies are further described and modelled in the next section. The identification of the load components are performed by analysing the total load curves in different periods of time. These studies have also been complemented with specific tests in order to characterise the load elements and models. Some of them will be described in the paper.

\section{A. UPV Load Analysis}

The UPV annual consumption was about 30 GWh in 2002 , and the load profile presents two well defined peaks: one about 1-2 pm and other in the evening (6-7 pm). The 8.1 MW summer power peak was in July.The load curves for the months of January, April and July of 2002 are shown in Fig. 5 .

The most important components present in the load mix are:

1) Space heating: From the UPV load curves inspection and comparing an average April labour day and the peak in a cold January day, it can be concluded that about $1.7 \mathrm{MW}$ of the winter peak $(19.1 \%)$ is due to space heating loads. An

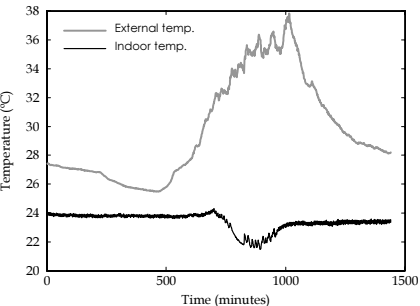

(a) Temperature evolution

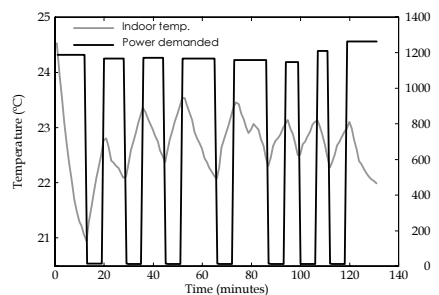

(b) Power demand
Fig. 6. UPV room conference AC load. Evolution of temperature (external and internal) and load demand dynamics

additional $5 \%$ can be attributed to conventional electric heaters and oil radiators placed in small individual offices, this demand is attributable to inefficiencies and human partners when a centralised conditioning system is present.

2) Air conditioning: The annual power peak in the UPV is the summer peak motivated by the air conditioning load. From the above load curves inspection, comparing an average April labour day with a hot summer day (August is a vacation month in Spain and the activity in the UPV is reduced to less than $40 \%$ ) it can be concluded that about $2.8 \mathrm{MW}$ of the peak summer (33-35\%) is due to air conditioning loads. In the last years, the traditional gas space heating systems are being replaced by heat pumps, that can provide service also in summer for space conditioning purposes. Several types of electric space conditioning elements (usually thermostatcontrolled) can be found in the UPV:

- Individual A/C elements. These are the older appliances, mainly window-type, rated a few $\mathrm{kW}$ and currently being replaced by more efficient systems.

- Split units, with good performance coefficients (COP, SEER).

- Compact units: with larger power rates and used for central building heating/cooling.

The evolution of the internal and external temperature in one UPV-office test is shown in Fig. 6(a) over a period span of 24 summer hours. As an example, the absorbed power is also shown for a two hours period from 2 to $4 \mathrm{PM}$ in the afternoon, in the same day — see Fig. 6(b)-.

An operation coefficient slightly higher than $70 \%$ (duty cycle) is observed in this Fig. 6(b), coefficient very dependent on the external temperature.

3) Lighting: The contribution of both outside and indoors lighting loads is very important in educational buildings [6] and therefore in the UPV load profile. From the study of the load curves and the time in which the ON switch of the outside lighting system is scheduled, it can be concluded that this load component amounts about $300 \mathrm{~kW}$ when the external illuminating system is switched on. The indoor lighting is the second consumption in UPV end use. About 23-27\% of peak demand is due to this component. Approximately up to 5\% of conventional fluorescent illumination is being changed to dimmable one -electronic ballasts and photosensors- due to energy efficiency purposes, specifically to profit daylight. 
4) Electronic equipment: Obviously the electronic equipment use -computers, printers, videos- in university buildings is very important. In the UPV case, this demand represents about $15-20 \%$ of overall peak demand. To identify this percentage the authors have used previous results based in non intrusive measurement at low aggregation levels [7]. The test procedure consisted on measuring harmonic components at the low voltage (380V, up to $100 \mathrm{~kW})$ and then reconstructing the harmonic measurements by weighting each end-use (specifically for electronic use) through an objective function. The algorithm implemented to analyse waveforms is transformedbased (like Fourier or Wavelet) with the difference that the mother waveforms are identified according to the current absorbed by each elemental load in a cycle.

5) Teaching and research labs: It is very difficult to estimate the share of this demand. The main reason for this difficulty is the unpredictable utilisation of these facilities. From a field sample performed in the laboratories of the two larger consume UPV buildings, a maximum demand lower than $10 \%$ can be forecasted.

6) Other demands: the rest of UPV demand (about 10\%) correspond to some miscellaneous uses, very difficult to characterize and not very useful for this paper.

7) Distributed Generation: There are some dispersed generation resources deployed in the university (diesel and gasturbine generators) that may be used as standby generators. The largest units are 630kVA rated (five units) and the overall capacity for generation amounts for about $4 \mathrm{MW}$.

\section{B. Demand Classification: Generation of Demand Bids}

According to the load suitability discussed in Section II and the analysis of III-A, the loads that conform the UPV demand will be grouped in the following load types:

- L1: Air conditioning and space heating loads. Different DP can be identified here (L1a, L1b,...) according to the power that could interrupted by cycle or total control of the different HVAC equipment.

- L2: Outdoor illumination loads. Two different sub-groups can be found here: the one formed by no interruptible lamps (L2a) and the one including interruptible lighting circuits (L2b, that are normally switched off in late night hours).

- L3: Indoor lighting. Two different sub-groups can also be found here: the one amounting the power necessary to have acceptable illumination levels (L3a) and other amounting the power that can be reduced by dimming some common areas or specific rooms (L3b).

- L4: the rest of the loads.

The demand necessities in the time horizon the energy is to be traded, need to be estimated and classified in the mentioned groups in order to produce the Demand Bids that will allow the UPV to buy the energy at the right price. Let us assume that energy is to be posted in one day ahead energy market and, then, this horizon is 24 hours.

The proposed methodology for the classification of the DP conforming the demand for this purpose considers the following steps:

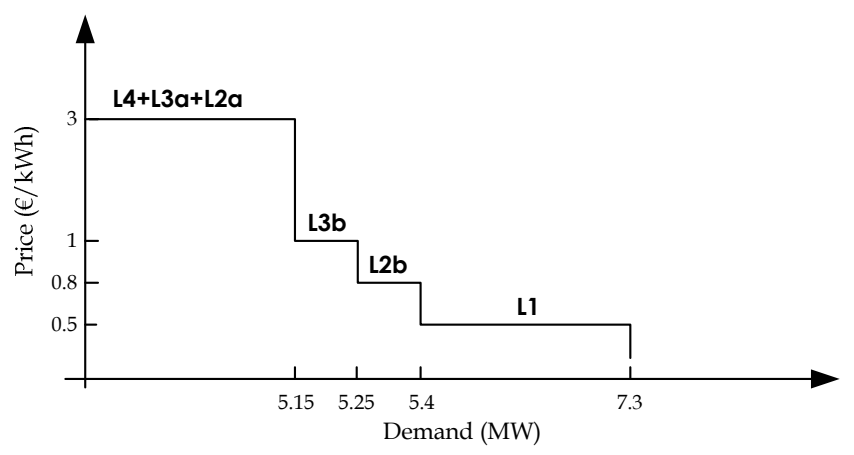

Fig. 7. UPV bids for the daily energy market for the winter peak hour

1) Perform 24 hours ahead demand forecasting and split this demand requirements for the above mentioned load groups. Use for that purpose all available information: type of day (labour or holyday, day of the week, Saturday or Sunday) and the forecasted (weather or other) parameters.

2) Form an hourly DP for the next 24 hours with the load regarded as critic (with no controlled reduction margin available). The loads considered in this group are: all L4 and the part of L2 and L3 that can not be interrupted (L3a, according to the minimum required illumination flows and the available dimming equipment and L2a, that is related to the existing separate circuits for outdoor illumination). Assign them a high decremental cost (2 $€ / \mathrm{kWh}$ ), as the involved equipment is basic to perform the normal activity.

3) Form, for the next 24 hours and in a hourly basis, separate DP corresponding to the rest of L3 (L3b) and L2 (L2b) that can be controlled, and for the whole L1 segment - all HVAC loads - . Assign to each of them a decremental cost, cost that will depend on several factors: the day of the week, the external temperature, and the estimated possible loss of comfort and induced absenteeism motivated for load interruption.

By using the demand packages identified so far in 2 and 3, the demand needs for the next day have been identified and the bids for one day ahead energy market can be produced by simply sending these DP (with specified hourly power requirements and cost) to the Power Exchange operator, who will settle the dispatch and the price for next day.

The demand bids, generated with the proposed methodology for the winter peak hour (January 29th, from 12 to $1 \mathrm{pm}$ ) are shown in Fig. 7.

The importance of electrical consuming processes in the UPV activity is considered to evaluate the price associated to each demand bid. For example L4, L3a and L2a packages are essential to develop teaching and research work and considering only the labour cost per man in an Spanish University, this factor supposes up to $20-25 \mathrm{k} € /$ year, moreover the annual electricity consumption is about $30 \mathrm{GWh} / \mathrm{year}$, and the hours worked in a year can be estimated as $2000 \mathrm{~h}$-man/year. Thus the cost of a $\mathrm{kWh}$ in our case is above $3 € / \mathrm{kWh}$. Additional cost of research are not considered here for simplicity. 
On the other side, without the demand included in L3b and $\mathrm{L} 2 \mathrm{~b}$, the normal university activity can progress with some minor changes. The necessity to perform some teaching activity rescheduling for indoor lighting regulation and the need to enhance security in the parking, and other areas of the UPV when the outdoor levels are reduced, have been considered to determine the value of the energy, resulting in 1 and $0.8 € / \mathrm{kWh}$ for L3b and L2b respectively.

The price evaluation for the last bid component (L1) has been performed through an estimation about the cost of replacement (substitution cost) of electrical heat pumps by double-effect absorption chillers (notice the university has, at present, a natural gas supply for some end-use, such are laboratories and distributed generation). The typical installed cost of these absorption chillers is about $450 € /$ ton, i.e $130 € / \mathrm{kW}$ installed, the mean cost of natural gas (8-9€/DkTherm) and the life of the equipment is estimated in 15 years. Thus, the change or dual primary supply alternative supposes an incremental cost over $0.5 € \mathrm{~kW} / \mathrm{h}$, and this is the price assigned to this demand component.

The Demand Packages regarded as critic will be probably (unless extreme conditions in the system are present) scheduled for dispatch and also will be the rest in most of the cases, as the cost of unavailability estimated for all of them are very high.

\section{Energy Packages: Demand Side Offers}

After the load that that will be dispatched the next day is known for the customer (for example, at noon in the previous day), the preparation of shorter term DP, aimed to reserve (primary, secondary or tertiary) and load balancing markets can be performed by defining the number of standard size DP (for example $0.05 \mathrm{MW}$, size that depends on the specific rules of the market to be addressed) and assigning them an increasing cost resulting from the loss of service produced by its implementation. The proposed DP specification procedure is as follows:

1) According to the results of for the energy market schedule, determine the amount of L1, L2b and L3b to be initially hourly scheduled for supply along the day.

2) Determine, using suitable demand models for every hour, the number of interruptible DP that can be offered in every hour of the next day in group L1, and the price for that, based on the extra cost derived both in the short term impact of the expected loss of comfort and the cost of the equipment to implement the required control. Several packages $(\mathrm{L} 1 \mathrm{a}, \mathrm{L} 1 \mathrm{~b}, \ldots)$ can be found, with different prices according to the severity of the control: the more power is offered, the highest is the impact of the loss of control and, then, the associated price.

Is basic, in order to evaluate the load availability and the associated price, to have accurate models in order to define the required control and evaluate its impact. The models assembled for this purpose will be described in the next section.
3) Determine, in the same way as in 2 , the number of interruptible packages and price L $2 \mathrm{~b}$ and $\mathrm{L} 3 \mathrm{~b}$. The associated price can be calculated accounting for customer loss of comfort, control monitoring and communication equipment costs.

The defined DP can be posted in the above mentioned markets, by following the specific market rules and times (ranking from some tens of minutes from balancing markets to hours for reserve or ancillary services).

The demand offers (load reduction) can be combined with other offers that can be generated by considering the use of stand-by generators. This generation offers are not considered here and they will be analysed in a further paper. Following the proposed procedure, the demand offers for the one day ahead energy market and ancillary services market can be produced.

In order to fully identify the DP that are going to conform the demand offers, two different problems have to be addressed: first, the modelling of the processes that are going to participate and, then, the control policies that guarantee the fulfilment of the offers. In the next section, the basis of the modelling philosophy is briefly presented and after that, the control strategies available for each load to perform offers are discussed and, finally, the application to the UPV offers is presented.

\section{A. Modeling}

Physically-based load modeling methodologies are the most promising approach for the load modelling problem applied to Demand Responsive evaluation purposes. A lot of models for HVAC, Water Heaters and ETS devices are described in the bibliography [3], [4]. The interest of these models is to forecast their behaviour when external actions are considered - Duty cycle modifications, voltage variations - to achieve a prefixed load curve. The modeling process has two steps: the first to achieve an elemental model, the second to aggregate these elemental models up to reach a useful controllable demand size.

The proposed elemental model relies on information about physical load characteristics - for example heat transfer processes-, internal control mechanisms - thermostat performance-, usage and environmental parameters. Obviously HVAC, ETS and lighting loads are the most important for this paper.

To obtain individual model parameters some tests are been carried out in eight representative rooms of a departmental building of the Polytechnic University of Valencia (Spain). Two days of voltage, current, power and temperature (external, internal and into the walls) measurements are performed every minute for two days in June 2002. Using an optimization algorithm and an initial value of our parameters, the output of a state-space equation model, describing our elemental model, is fitted to the real behavior, [5].

The second step has consisted in aggregating the response of elemental loads. This problem consists on describing -for a given load control group, i.e. a set of elemental electrical appliances-, approximately the expected value of the total power demand due to the group. This problem can be solved 
through an ensemble of mathematical tools. For example by Fokker-Planck equations, or Monte-Carlo methods described in previous papers, [8].

\section{B. Control Strategies}

The use of load control actions to modify demand curves has been used since early sixties in the 20th century, but their objectives need to evolve from the supply side Direct Load Control (DLC) in traditional DSM programs to the those that implies the voluntary participation of the demand through demand offers. It is therefore necessary to develop new specific policies and improve existing tools to manage, forecast and evaluate the possibilities to perform offers for load reduction in deregulated market scenarios. The demand control strategies to achieve the required control objectives are shown in Table I.

Each responsive policy has different objectives according to bid and offer implementation necessities. For example an user who expects to offer a demand package reduction should control the demand of only the appropriate kind of load: HVAC, ECTS, lighting, etc. It is well known, from DSM experiences described in the bibliography, that payback periods follows up any control action. To reduce payback is necessary to apply additional actions - with ETS or lighting loads-, as proposed in Table I.

\section{Cost Analysis and Application}

It is necessary, in order to fully describe the demand offers resulting from Active Demand participation in electricity markets, to determine the involved cost so that the price for these offers can be set up. This cost computation procedure could be as follows:

1) Perform a market analysis, to estimate the number of hours and frequency in each season that the consumer load offer is to be accepted in electricity markets. From reported experiences from USA and UK markets along the lasts years [2], [9] about $100 \mathrm{~h} /$ year in 20 to 40 events/year can be expected.

2) Determine the cost of the demand control, including the one derived from the reduction of the comfort, the cost of control mechanisms, the cost of storage reservoirs when ETS loads are present and the operation and maintenance cost of the energy management system. Finally, it is also necessary to perform an energy balance to determine the surplus of energy recovered during the payback periods, [10].

The methodology proposed in this section has been applied to determine the UPV demand offers for the summer demand peak hour(July 9, 2002, 1 to $2 \mathrm{PM}$ ), and the results are shown in Fig. 8.

The power reduction offered corresponds basically to Air Conditioning loads (L1) and a small amount internal lightning loads (L3).

For the evaluation of the size and cost associated to L3b (indoor lighting loads), a $20 \%$ of illumination equipment is assumed to have dimmable ballast and photosensors as well as

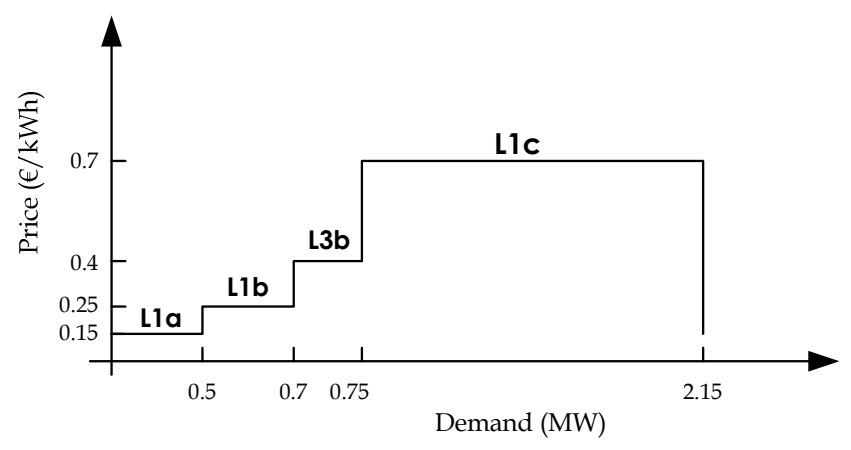

Fig. 8. UPV demand offers for July 9, 2002, 1 to 2 PM

the required communication and control equipment (life cycle is supposed to be 15 years). It is estimated that only about $10 \%$ of this equipment was switched on during the summer peak.

The evaluation of $\mathrm{L} 1$ reduction offer is more complex, as the size of the offered package is inversely proportional to user comfort reduction. Obviously, the larger the reduction of power is, the farther the temperature will be above the thermostat set-point and, consequently, the loss of comfort. Therefore, the evaluation of the behavior of the internal temperature as well as the control equipment costs have to be accounted for this offer size and cost determination.

L1 package has been split into three sub-packages for this purpose: the first package, L1a, accounts for a demand reduction that supposes an average rise in internal temperature lower than $2^{\circ} \mathrm{C}$. The second package, L1b, forces the energy management system to apply a more several control (internal temperatures $4^{\circ} \mathrm{C}$ above the thermostat setpoint are expected in the simulation). Finally the interruption of the rest of the AC load is considered for L1c offer.

\section{Simulation Results}

A simulation of the acceptance of the UPV demand offers as described in the previous section- has been performed and is described in this paragraph. It is supposed a balancing market clearing price of $0.15 € / \mathrm{kWh}$, and, according to the offers stated in figure, five standard DP ( $5 \times 0.1 \mathrm{MWh})$ average power has to be curtailed during a period estimated in three hours.

UPV Air Conditioning load is divided into 20 control groups, with similar size (100-200 kW/group) and the UPV energy management system is programmed to apply different ON/OFF cycling control policies during the control period (from $11 \mathrm{~h}$ to $15 \mathrm{~h}$ ), in order to target reference strategy and achieve the offered load reduction (the five $0.1 \mathrm{MW}$ packages). The actual consumption is also shown in Fig. 9, where a payback period of about 4 hours is observed, and has to be accounted for in the rest of the offers.

Some factors, such as loss of control or other equipment or deceit by the end users, may prevent the consecution of the control objectives. This has also been simulated and the effects are shown in the Fig. 9. These deviations can be either corrected with additional control actions.

The expected average internal temperature for the UPV offices and classrooms is shown in Fig. 10, where it can be 


\begin{tabular}{ccc}
\hline Demand resp. policy & Package & Control strategies \\
\hline Demand limiting & L1,L2b,L3b & Cycling, dimming \\
Demand filling & L1, L2b, ETS & Cycling, preheating, precooling \\
Damp reduction & L3b, ETS partial & Dimming ballasts, control of storage reservoir \\
Demand Static Reserve & L1, L2b, L3b & Shed load, dimming \\
\hline
\end{tabular}

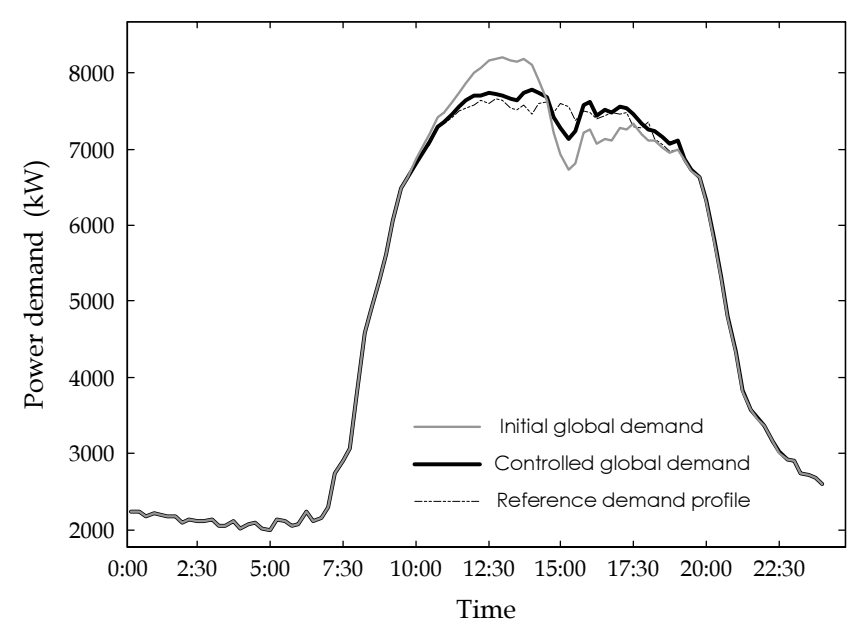

Fig. 9. Direct Load Control of AC loads. Summer peak demand

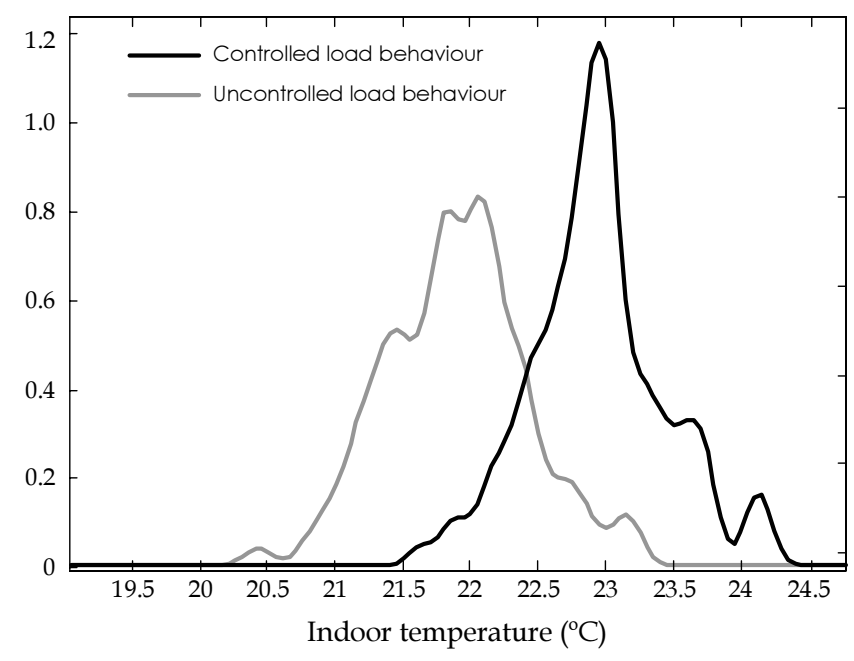

Fig. 10. Probability density function for internal temperature with and without offer implementation

observed that only an average deviation of 1.5 degree with respect to the same temperature without implementing that offer is associated to this L1a offer.

\section{CONClusion}

The implementation of electric energy markets is quite doubtful without the active participation of the demand. A methodology, suitable for large customers or aggregators, oriented to enhance the participation of the electricity demand in organised electricity markets is presented in this paper. The proposed customer driven demand participation contrasts with the traditional supply oriented DSM programs in the way that this participation is always customer decided (voluntary).

A discussion of the load elements that can help in this active participation is first presented in the paper. The new methodology, well suited for the possible participation both medium and short term markets, is presented afterwards, methodology that is based on the detailed knowledge of the load elements and processes involved in the customer load mix.

The implementation of the proposed methodology requires an accurate forecasting of the load components over the time the demand bids and offers are to be traded. Moreover, a detailed analysis of the flexibility of the involved processes together with advanced simulation tools are required in order to help the consumer identify the demand side bids and offers that is capable to generate in a realistic way.

The proposed methodology is applied to the case of a large university customer - Universidad Politécnica de Valencia-, application that is used to point out the main steps and issues related to its implementation. The simulations performed are oriented both to define the demand offers as well as to simulate the results of its implementation.

\section{ACKNOWLEDGMENT}

The work described in this paper is financially supported by the Ministerio de Ciencia y Tecnología of Spain through a research project (DPI2001-2779-C02-01).

\section{REFERENCES}

[1] N. S. Rau, "Assigment of capability obligation to entities in competitive markets: the concept of reliability equity," IEEE Trans. on Power Systems, vol. 14, no. 3, pp. -, August 1999.

[2] E. Hirst and B. Kirby, "Retail-load participation in competitive wholesale electricity markets," Prepared for Edision Electric Institute, January 2001.

[3] C. Alvarez, R. Malhamé, and A. Gabaldón, "A class of models for load management application and evaluation revisited," IEEE Trans. on Power Systems, vol. 7, no. 4, pp. 1435-1443, November 1992.

[4] A. Gomes, A. G. Martins, and R. Figueiredo, "Simulation-based assessment of electric load management programs," I. J. of Energy Research, vol. 23, pp. 169-181, 1999.

[5] A. Molina, A. Gabaldón, J. A. Fuentes, and C. Álvarez, "Implementation and assessment of physically based electrical load models: application to direct load control residential programmes," IEE Proceedings on Gener. Transm. and Distribution, vol. 150, pp. 61-66, January 2003.

[6] S. G. Instituto para la Diversificación y Ahorro de Energía, "Technical guide for energy efficiency in lighting," http://www.idae.org, March 2001.

[7] J. Fuentes, A. Gabaldón, A. Molina, and E. Gómez, "Development and assessment of a load decomposition method applied to distribution level," IEE Proceedings on Gener. Transm. and Distribution, vol. 150, no. 2, pp. 245-251, March 2003. 
[8] A. Molina, A. Gabaldón, M. Kessler, and J. A. Fuentes, "Application of smothing techniques to solve the cooling and heating residential load aggregation problem," in VII International Conference on Probabilistic Methods Applied to Power Systems, vol. 2, 2002, pp. 879-886.

[9] D. Grayson, C. Heffner, and C. A. Goldman, "Demand responsive programs. an emerging resource for competitive electricity markets?" Proc. on International Energy program evaluation conference (IEPEC), 2001.

[10] G. Strubac and D. Kirschen, "Assessing the competitive of demand-side bidding," IEEE Trans. on Power Systems, vol. 14, no. 1, pp. 120-125, February 1999.

Carlos Alvarez (Cuenca, Spain, 1954). He received his MSc and PhD in Electrical Engineering from the Universidad Politécnica de Valencia (UPV), where he is Professor since 1989. His professional activity has been performed in the electric energy systems field in utilities, research programs and projects. $\mathrm{He}$ has conducted, in the last 5 years, about 10 funded research projects with Spanish utilities in the areas of Distribution Systems, Power Quality, Environmental Impact and technology evaluation and development. He has been involved in several projects in the field of Demand Side Management in Europe, USA and Canada. One of his main current work is in the area of the Flexible Energy Delivery Systems and commercialization of the electric energy in free market environments, with emphasis in techniques and methods to enhance the active participation of the demand. E-mail: calvarez@ die.upv.es

Antonio Gabaldón received his Electrical Engineering degree from Universidad Politécnica de Valencia, Spain, in 1988, and his Ph.D. degree from the same University in 1991. Currently, he is working with the Department of Electrical Engineering of Universidad Politécnica de Cartagena, Spain. His research interests include Demand-Side Management, Demand-side Bidding, end-use efficiency, load modeling and Distribution Automation. E-mail: antonio.gabaldon@upct.es

Angel Molina received his Electrical Engineering degree from Universidad Politécnica de Valencia, Spain, in 1998. Currently, he is working towards his $\mathrm{Ph} . \mathrm{D}$. at Department of Electrical Engineering of Universidad Politécnica de Cartagena, Spain. His research interests include Demand-Side Management, Demand-Side Bidding, adaptive predictive control, load modeling, theory and its direct load control applications. E-mail: angel.molina@upct.es 